\begin{tabular}{|c|l|}
\hline Title & Expression of recombinant sea urchin cellulase SnEG54 using mammalian cell lines \\
\hline Author(s) & Okumura, Fumihiko; Kameda, Hiroyuki; Ojima, Takao; Hatakey ama, Shigetsugu \\
\hline Citation & $\begin{array}{l}\text { Biochemical and Biophysical Research Communications, 395(3), 352-355 } \\
\text { https://doi.org/40.1016/.bbrc.2010.04.016 }\end{array}$ \\
\hline Issue Date & 2010-05-07 \\
\hline Doc URL & http://hdl.handle.net/2115/43096 \\
\hline Type & article (author version) \\
\hline File Information & BBRC395-3_352-355.pdf \\
\hline
\end{tabular}

Instructions for use 


\title{
Expression of recombinant sea urchin cellulase SnEG54 using mammalian cell lines
}

\author{
Fumihiko Okumura a, Hiroyuki Kameda a, Takao Ojima ${ }^{\text {b and Shigetsugu }}$ \\ Hatakeyama $^{\text {a, } *}$
}

${ }^{\text {a }}$ Department of Biochemistry, Hokkaido University Graduate School of Medicine, Kita 15, Nishi 7, Kita-ku, Sapporo, Hokkaido 060-8638, Japan.

b Laboratory of Marine Biotechnology, Graduate School of Fisheries Sciences, Hokkaido University, 3-1-1 Minato-cho, Hakodate, Hokkaido 041-8611, Japan.

* Corresponding authors. Shigetsugu Hatakeyama, Department of Biochemistry, Hokkaido University Graduate School of Medicine, N15, W7, Kita-ku, Sapporo, Hokkaido 060-8638, Japan. Phone: +81 11706 5899; Fax: +81 11706 5169; E-mail address: hatas@med.hokudai.ac.jp (S. Hatakeyama).

Keywords: sea urchin, Stronglyocentrotus nudus, cellulase, HeLa, HEK293T 


\begin{abstract}
We previously identified the cellulase SnEG54 from Japanese purple sea urchin Strongylocentrotus nudus, the molecular mass of which is about $54 \mathrm{kDa}$ on SDS-PAGE. It is difficult to express and purify a recombinant cellulase protein using bacteria such as E. coli or yeast. In this study, we generated mammalian expression vectors encoding SnEG54 to transiently express SnEG54 in mammalian cells. Both SnEG54 expressed in mammalian cells and SnEG54 released into the culture supernatant showed hydrolytic activity toward carboxymethyl cellulose. By using a retroviral expression system, we also established a mammalian cell line that constitutively produces SnEG54. Unexpectedly, SnEG54 released into the culture medium was not stable, and the peak time showing the highest concentration was approximately 1 to 2 days after seeding into fresh culture media. These findings suggest that non-mammalian sea urchin cellulase can be generated in human cell lines but that recombinant SnEG54 is unstable in culture medium due to an unidentified mechanism.
\end{abstract}




\section{Introduction}

The cell wall of a higher plant mainly consists of cellulose, which is a linear polysaccharide consisting of $\beta$-1,4-linked D-glucose residues. Cellulase hydrolyzes $\beta$-1,4-glycosyl linkages of the cellulose chain, producing cellooligosaccharides such as cellotriose and cellobiose [1]. Cellulase is roughly divided into two groups, endolytic (endo-1,4- $\beta$-glucanase, EC 3.2.1.4) and exolytic (cellobiohydrolase, EC 3.2.1.91) groups. 1,4- $\beta$-glucosidase (EC 3.2.1.21) is required for complete de-polymerization of cellulose to glucose. These enzymes have been isolated from bacteria and fungi [1], plants [2], molds [3], microbes from animal intestines [4], and herbivorous invertebrates such as arthropods [5-10], nematodes [10], mollusks [11-16] and an echinoderm [17]. So far, over one hundred glycoside hydrolase families (GHFs) have been identified by hydrophobic cluster analysis of the primary structure [18]. The majority of animal cellulases belong to GHF9 and a cellulase from sea urchin, SnEG54, was also classified under GHF9 [17]. SnEG54 exhibited a high level of hydrolytic activity toward carboxymethyl cellulose $(\mathrm{CMC})$ at $35^{\circ} \mathrm{C}$ and $\mathrm{pH} 6.5$ and also degraded a cellulose polymer and cellooligosaccharides larger than cellotriose, producing cellotriose and cellobiose, but not small cellooligosaccharides [17]. Efficient production of cellulose-derived glucose by cellulase has recently become a socially important issue in the world because glucose is available for fermentation of ethanol, which can be used as a biomass-derived fuel. Thus, cellulose-degrading enzymes have been attracting the attention of many researchers involved in studies on saccharification of cellulosic materials and production of biofuels [19].

A retroviral expression system is an important tool for gene transfer applications. 
Introduction of retroviral vectors containing the gene of interest into suitable packaging cells enables production of infectious retroviruses, and these particles can infect target cells and stably transmit the gene of interest into chromosomes. Platinum-E (Plat-E) is one of the retrovirus packaging cell lines generated on the basis of the HEK293T cell line [20]. Plat-E is superior to existing packaging cell lines in efficiency, stability and safety. Mouse type $\mathrm{C}$ ecotropic retrovirus infection is initiated by virus envelope binding to a membrane receptor expressed on mouse cells. The mCAT-1 protein has been identified as a receptor for mouse type $\mathrm{C}$ ecotropic retrovirus and it has acquired susceptibility to infection by the retrovirus [21]. Introduction of the mCAT1 gene is effective for improving transduction efficiency for human cell lines [22].

In this study, we transfected an expression vector encoding SnEG54 cDNA into mammalian cell lines and confirmed cellulase activity of recombinant SnEG54 produced by mammalian cells. Both SnEG54 in the cytosol and SnEG54 secreted into the culture medium showed hydrolytic activity toward CMC. Furthermore, using a retroviral expression system, we established a mammalian cell line that continuously secretes SnEG54 into the culture medium. Since the production of recombinant GHF-9 cellulases in active form in bacteria or yeast cells is difficult, there has been little progress in protein-engineering studies on GHF-9 cellulases. Therefore, an expression system capable of producing active GHF-9 cellulases will become a useful tool for structure-function studies on this enzyme. Here, we report the successful production of a sea urchin GHF-9 cellulase, SnEG54, using mammalian expression vectors and a human cell line. 


\section{Materials and methods}

Plasmid construction. SnEG54 cDNAs without a stop codon were amplified from pCR2-SnEG54 cDNA [17] by PCR with KOD (Toyobo, Tokyo, Japan) using the following primers: 5'-GCCATGTTGCCTTTAATCTTG-3' (SnEG54-sense) and 5'-CATGTTGAGTTGCTTGAGGCC-3' (SnEG54-antisense). The amplified fragments were subcloned into pBluescript II SK+ (Stratagene, La Jolla, CA) at the EcoRV site (pBS-SnEG54). pBS-SnEG54 was digested with EcoRI and SalI and ligated into pcDNA3-MycHisA (Invitrogen, Carlsbad, CA) (pcDNA3-MycHis-SnEG54). pcDNA3-MycHis-SnEG54 was digest with BamHI and PmeI and ligated into pMX-puro (pMX-puro-SnEG54-Myc).

Cell culture and transfection. HEK293T and HeLa cell lines were cultured under an atmosphere of $5 \% \mathrm{CO}_{2}$ at $37^{\circ} \mathrm{C}$ in DMEM (Sigma, St. Louis, MO) supplemented with $10 \%$ fetal bovine serum (Invitrogen, Carlsbad, CA). 293T cells were transfected using calcium phosphate precipitation as described previously [23]. For small-scale transfection, Fugene HD reagent was used according to the protocol of the manufacturer (Roche, Indianapolis, IN).

Transfection and immunoblot analysis. Cells were lysed in a solution containing 50 mmol/l Tris- $\mathrm{HCl}$ (pH 7.4), 150 mmol/1 NaCl, $1 \%$ Nonidet P-40, leupeptin (10 $\mu \mathrm{g} / \mathrm{ml}), 1$ mmol/l phenylmethylsulfonyl fluoride, $400 \mu \mathrm{mol} / 1 \mathrm{Na}_{3} \mathrm{VO}_{4}, 400 \mu \mathrm{mol} / \mathrm{l}$ EDTA, 10 $\mathrm{mmol} / \mathrm{l} \mathrm{NaF}$, and $10 \mathrm{mmol} / \mathrm{l}$ sodium pyrophosphate. The cell lysates were centrifuged at $16,000 \times \mathrm{g}$ for $10 \mathrm{~min}$ at $4^{\circ} \mathrm{C}$ and then boiled in SDS sample buffer. Immunoblot analysis was performed with the following primary antibodies: anti-Myc $(1 \mu \mathrm{g} / \mathrm{ml}$; 9E10, Covance, Berkeley, CA) and anti- $\beta$-actin ( $1 \mu \mathrm{g} / \mathrm{ml}$; AC15, Sigma). Immune complexes 
were detected with horseradish peroxidase-conjugated antibodies to mouse $\operatorname{IgG}$ (1:10,000 dilution, Promega, Madison, WI) and an enhanced chemiluminescence system (Amersham Pharmacia Biotech Inc, Piscataway, NJ).

Assay for cellulase activity. Standard assay for cellulase activity was carried out with a reaction mixture containing $0.5 \% \mathrm{CMC}, 10 \mathrm{mM}$ sodium phosphate $(\mathrm{pH} 7.0)$, and $0.05-5 \mathrm{U} / \mathrm{ml}$ of cellulase at $30^{\circ} \mathrm{C}$. Reducing sugar produced by the reaction was determined by the method of Nelson and Somogyi [24]. One unit of cellulase was defined as the amount of enzyme that produces reducing sugar equivalent to $1 \mathrm{mmol}$ of glucose for $1 \mathrm{~min}$. Crude extracts from transfected cells or the culture supernatant were incubated with $\mathrm{CMC}$ at $35^{\circ} \mathrm{C}$ and $\mathrm{pH} 6.5$, and the absorptions were measured at $690 \mathrm{~nm}$.

Establishment of stable transfectants by using a retrovirus expression system. Complementary DNAs were subcloned into pMX-puro (kindly provided by T. Kitamura, Tokyo University), and the resulting vectors were used to transfect Plat E cells and then recombinant retroviruses were generated. HeLa cells stably transfected with mCAT-1 were infected with the recombinant retroviruses and selected in medium containing puromycin $(1 \mu \mathrm{g} / \mathrm{ml}$, Sigma).

Stability of SnEG54 secreted in culture medium. HeLa cells stably expressing SnEG54 and Mock were plated on 6-cm dishes (day 0) with $4 \mathrm{ml}$ of culture medium without bovine calf serum. Each culture medium was harvested every day up to day 4 . Ten and forty $\mu$ were subjected to immunoblotting and Coomassie Brilliant Blue staining, respectively. 


\section{Results}

Expression of SnEG54 in a mammalian cell line

To examine whether non-mammalian sea urchin protein SnEG54 can be expressed and secreted by a human cell line, we constructed an expression vector encoding Myc-tagged SnEG54 at the carboxy terminus (pcDNA3-MycHis-SnEG54). pcDNA3-MycHis-SnEG54 was transfected into HEK293T cells by the $\mathrm{CaPO}_{4}$ method. Cell lysates were prepared two days after transfection and subjected to SDS-PAGE and immunoblotting with anti-Myc antibody to detect Myc-tagged SnEG54 in the cytosol and in the culture medium. Immunoblot analysis showed that transfected HEK293T cells produced SnEG54 both in the cytosol and in the culture medium (Fig. 1). A putative degraded form of SnEG54 was found abundantly in the cytosol compared to that in the culture medium.

\section{Cellulase activity of SnEG54 expressed in mammalian cells}

Next, we examined cellulase activity of SnEG54 prepared from the cytosol and the culture medium as reported previously [17]. pcDNA3-MycHis-SnEG54 (20 $\mu \mathrm{g})$ or Mock was transfected into HEK293T cells $\left(3 \times 10^{6}\right.$ cells $/ 10 \mathrm{ml}$ culture medium). The cells were cultured for $48 \mathrm{hrs,}$ and then the cells and culture supernatants were collect to measure cellulase activities. As expected, mock-transfected cell lysates as well as the culture medium did not show cellulase activity (Fig. 2). On the other hand, cell lysates from SnEG54-transfected cells showed cellulase activity $(0.2 \mathrm{U} / \mathrm{ml})$. Most importantly, 
the culture supernatant derived from SnEG54-transfected cells also showed cellulase activity $(0.037 \mathrm{U} / \mathrm{ml})$, suggesting that recombinant SnEG54 proteins was properly translated, folded, and secreted into the culture medium (Fig. 2).

Establishment of a mammalian cell line stably expressing SnEG54

HeLa cells in which mCAT-1 was stably expressed were infected with retroviruses encoding Myc-tagged SnEG54 and selected with puromycin to establish a cell line stably expressing SnEG54. To examine whether the selected cell line expresses and secretes SnEG54, we performed immunoblot analysis with anti-Myc antibody. As expected, Myc-tagged SnEG54 was expressed in this cell line and was also secreted into the culture supernatant (Fig. 3). If SnEG54 from this cell line was secreted into the culture medium, SnEG54 should be gradually concentrated in the culture medium. To investigate this hypothesis, we harvested the culture medium every day for four days and compared the concentrations of SnEG54. Surprisingly, although SnEG54 was clearly detected in the culture medium on days 1 and 2, it had disappeared on days 3 and 4 (Fig. 4). These findings suggest that recombinant SnEG54 is unstable in culture medium due to an unidentified mechanism. 


\section{Discussion}

Production of bioethanol as a fuel from recycling of biomass resources is important to reduce emission of carbon dioxide to the environment (air pollution). So far, bioethanol has been produced mainly from corn and wheat and has been mostly used as gasoline additives. To produce 10 million tons of bioethanol from grains, about 30 million tons of grains is needed [25]. Materials other than foods should be used for bioethanol production because producing more bioethanol from grains endangers food supply. A wood hydrolysis factory has been using an acid hydrolysis process to produce 4,000 tons of bioethanol per year [25]. Although cellulosic bioethanol does not endanger food supply directly, the cost of producing cellulosic bioethanol by this acid hydrolysis process is still higher than that of corn ethanol, partly because of its lower yield caused by over-hydrolysis to toxic by-products and the non-fermentability of pentoses [25]. It has been reported that several isolated mutants of Penicillium decumbens can produce large amounts of cellulases in the presence of a high concentration of soluble sugars, but they cannot be used for glucose production due to high prices [26]. It is not a good idea to use wood and food for the production of bioethanol from the point of view of environmental protection and food supply. For example, rice straw is a good candidate for production of bioethanol. Furthermore, if sugar can be produced from rice straw, it may be possible to overcome the problem of food shortages to some extent. To achieve this, we need to utilize cellulases that have low cost and are safe enough for food production. The use of bacteria, fungi or molds would be an easy way to obtain cellulases. However, it is difficult to produce

recombinant cellulase using these organisms. Therefore, we tried to express a 
non-mammalian GHF-9 cellulase, SnEG54, using human cell lines and we established a mammalian cell line that stably expresses SnEG54. This established cell line constitutively expressed SnEG54, and recombinant SnEG54 could be easily withdrawn from the culture supernatants.

Although SnEG54 was successfully produced by a mammalian cell line as an active form, it was degraded within a few days (Fig. 4). If we could inhibit the degradation of secreted SnEG54, we may be able to obtain higher activity of cellulases for in vitro degradation of cellulose. Moreover, eukaryotic cell culture is costly and improvements must be made to maintain the culture system at a low cost in the future. Furthermore, it would be interesting to generate a transgenic mouse expressing SnEG54, in which SnEG54 is expressed especially in the digestive tract, and to examine whether the SnEG54 transgenic mouse can catabolize dietary fibers and use celluloses as an energy source. 


\section{Acknowledgments}

We would like to thank K. Hanada and T. Kitamura for the plasmids and cell lines and Y. Soida for helping with preparation of the manuscript.

This work was supported in part by a research grant from Grant-in-Aid for Scientific Research on Priority Areas from the Ministry of Education, Culture, Sports, Science and Technology, Ono Cancer Research Fund, The Ichiro Kanehara Foundation, The Nakatomi Foundation, Japan Brain Foundation and the Research Foundation Ituu Laboratory (to S. Hatakeyama). 


\section{References}

[1] P. Tomme, R.A. Warren, N.R. Gilkes, Cellulose hydrolysis by bacteria and fungi, Adv. Microb. Physiol. 37 (1995) 1-81.

[2] D.A. Brummell, C. Catala, C.C. Lashbrook, A.B. Bennett, A membrane-anchored E-type endo-1,4-beta-glucanase is localized on Golgi and plasma membranes of higher plants, Proc. Natl. Acad. Sci. USA 94 (1997) 4794-4799.

[3] J.E. Blume, H.L. Ennis, A Dictyostelium discoideum cellulase is a member of a spore germination-specific gene family, J. Biol. Chem. 266 (1991) 15432-15437.

[4] S. Moriya, M. Ohkuma, T. Kudo, Phylogenetic position of symbiotic protist Dinenympha [correction of Dinemympha] exilis in the hindgut of the termite Reticulitermes speratus inferred from the protein phylogeny of elongation factor 1 alpha, Gene 210 (1998) 221-227.

[5] H. Watanabe, M. Nakamura, G. Tokuda, I. Yamaoka, A.M. Scrivener, H. Noda, Site of secretion and properties of endogenous endo-beta-1,4-glucanase components from Reticulitermes speratus (Kolbe), a Japanese subterranean termite, Insect Biochem. Mol. Biol. 27 (1997) 305-313.

[6] H. Watanabe, H. Noda, G. Tokuda, N. Lo, A cellulase gene of termite origin, Nature 394 (1998) 330-331.

[7] G. Tokuda, N. Lo, H. Watanabe, M. Slaytor, T. Matsumoto, H. Noda, Metazoan cellulase genes from termites: intron/exon structures and sites of expression, Biochim. Biophys. Acta 1447 (1999) 146-159.

[8] A.C. Crawford, J.A. Kricker, A.J. Anderson, N.R. Richardson, P.B. Mather, Structure and function of a cellulase gene in redclaw crayfish, Cherax quadricarinatus, Gene 340 (2004) 267-274.

[9] H. Watanabe, G. Tokuda, Animal cellulases, Cell Mol. Life Sci. 58 (2001) 1167-1178.

[10] M. Sugimura, H. Watanabe, N. Lo, H. Saito, Purification, characterization, cDNA cloning and nucleotide sequencing of a cellulase from the yellow-spotted longicorn beetle, Psacothea hilaris, Eur. J. Biochem. 270 (2003) 3455-3460.

[11] Y. Yokoe, I. Yasumasu, The Distribution of Cellulase in Invertebrates, Comp. Biochem. Physiol. 13 (1964) 323-338.

[12] J.J. Marshall, Purification of a -1,4-glucan hydrolase (cellulase) from the snail, Helix pomatia, Comp. Biochem. Physiol. B 44 (1973) 981-988.

[13] J.J. Marshall, R.J. Grand, Characterization of a beta-1,4-glucan hydrolase from the 
snail, Helix pomatia, Comp. Biochem. Physiol. B 53 (1976) 231-237.

[14] H. Anzai, K. Nisizawa, K. Matsuda, Purification and characterization of a cellulase from Dolabella auricularia, J. Biochem. 96 (1984) 1381-1390.

[15] K. Suzuki, T. Ojima, K. Nishita, Purification and cDNA cloning of a cellulase from abalone Haliotis discus hannai, Eur. J. Biochem. 270 (2003) 771-778.

[16] J. Wang, M. Ding, Y.H. Li, Q.X. Chen, G.J. Xu, F.K. Zhao, Isolation of a multi-functional endogenous cellulase gene from mollusc, Ampullaria crossean, Sheng Wu Hua Xue Yu Sheng Wu Wu Li Xue Bao (Shanghai) 35 (2003) 941-946.

[17] Y. Nishida, K. Suzuki, Y. Kumagai, H. Tanaka, A. Inoue, T. Ojima, Isolation and primary structure of a cellulase from the Japanese sea urchin Strongylocentrotus nudus, Biochimie 89 (2007) 1002-1011.

[18] B. Henrissat, G. Davies, Structural and sequence-based classification of glycoside hydrolases, Curr Opin Struct Biol 7 (1997) 637-644.

[19] Y. Lin, S. Tanaka, Ethanol fermentation from biomass resources: current state and prospects, Appl. Microbiol. Biotechnol. 69 (2006) 627-642.

[20] S. Morita, T. Kojima, T. Kitamura, Plat-E: an efficient and stable system for transient packaging of retroviruses, Gene Ther. 7 (2000) 1063-1066.

[21] L.M. Albritton, L. Tseng, D. Scadden, J.M. Cunningham, A putative murine ecotropic retrovirus receptor gene encodes a multiple membrane-spanning protein and confers susceptibility to virus infection, Cell 57 (1989) 659-666.

[22] K. Hanada, K. Kumagai, S. Yasuda, Y. Miura, M. Kawano, M. Fukasawa, M. Nishijima, Molecular machinery for non-vesicular trafficking of ceramide, Nature 426 (2003) 803-809.

[23] F. Okumura, W. Zou, D.E. Zhang, ISG15 modification of the eIF4E cognate 4EHP enhances cap structure-binding activity of 4EHP, Genes Dev. 21 (2007) 255-260.

[24] N.B. Nelson, H.I. Sauer, Tuberculosis in Los Angeles: A Joint Health Department and Tuberculosis Association Study in Organizing Facts for Program Planning, Cal West Med 61 (1944) 95-96.

[25] Q. Yinbo, M. Zhu, K. Liu, X. Bao, J. Lin, Studies on cellulosic ethanol production for sustainable supply of liquid fuel in China, Biotechnol. J. 1 (2006) 1235-1240.

[26] Y.B. Qu, X. Zhao, P.J. Gao, Z.N. Wang, Cellulase production from spent sulfite liquor and paper-mill waste fiber. Scientific note, Appl. Biochem. Biotechnol. 28-29 (1991) 363-368. 


\section{Figure legends}

Fig. 1. Expression of SnEG54 in HEK293T cells. HEK293T cells cultured with $10 \mathrm{ml}$ medium were transfected with a plasmid encoding carboxy-terminal Myc-tagged SnEG54. Two days after transfection, $2 \%$ of the lysate (WCL) and $0.05 \%$ of the culture medium (Sup) were subjected to immunoblotting (IB) with anti-Myc antibody.

Fig. 2. Cellulase activity of SnEG54 expressed in mammalian cells. Crude extracts from transfected cells or the culture supernatant were incubated with $\mathrm{CMC}$ at $35^{\circ} \mathrm{C}$ and $\mathrm{pH}$ 6.5 and the absorptions were measured at $690 \mathrm{~nm}$.

Fig. 3. HeLa cell line stably expressing SnEG54. $1 \%$ of the cell lysate (WCL) and $0.1 \%$ of the culture medium (Sup) of SnEG54- or mock-expressing HeLa cells were subjected to immunoblotting with anti-Myc antibody. Anti- $\beta$-actin antibody was used as a loading control.

Fig. 4. Expression level of SnEG54 secreted from the stable cell line in culture medium. Culture media from SnEG54- or mock-expressing HeLa cells were harvested every day and subjected to immunoblotting with anti-Myc antibody and stained with Coomassie Brilliant Blue R-250 as a loading control. Bovine serum albumin (BSA) of several concentrations was used as loading controls. 


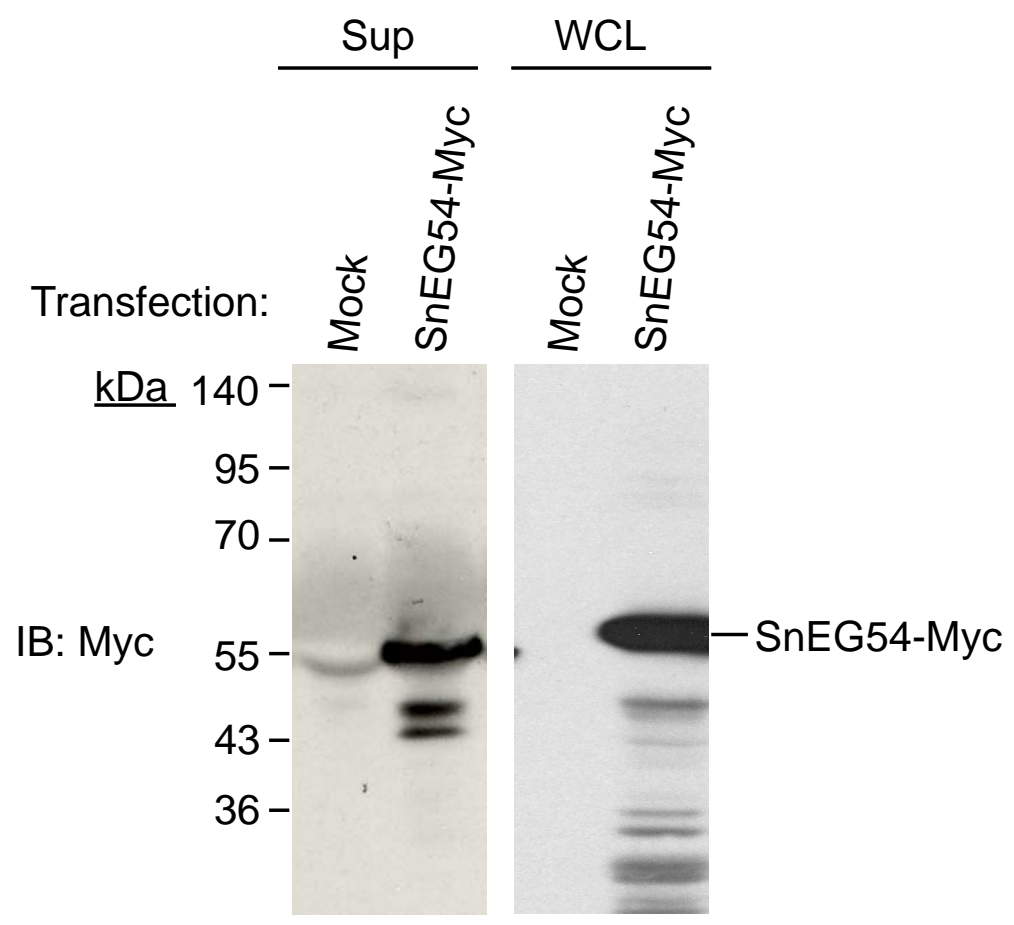

Fig. 1 


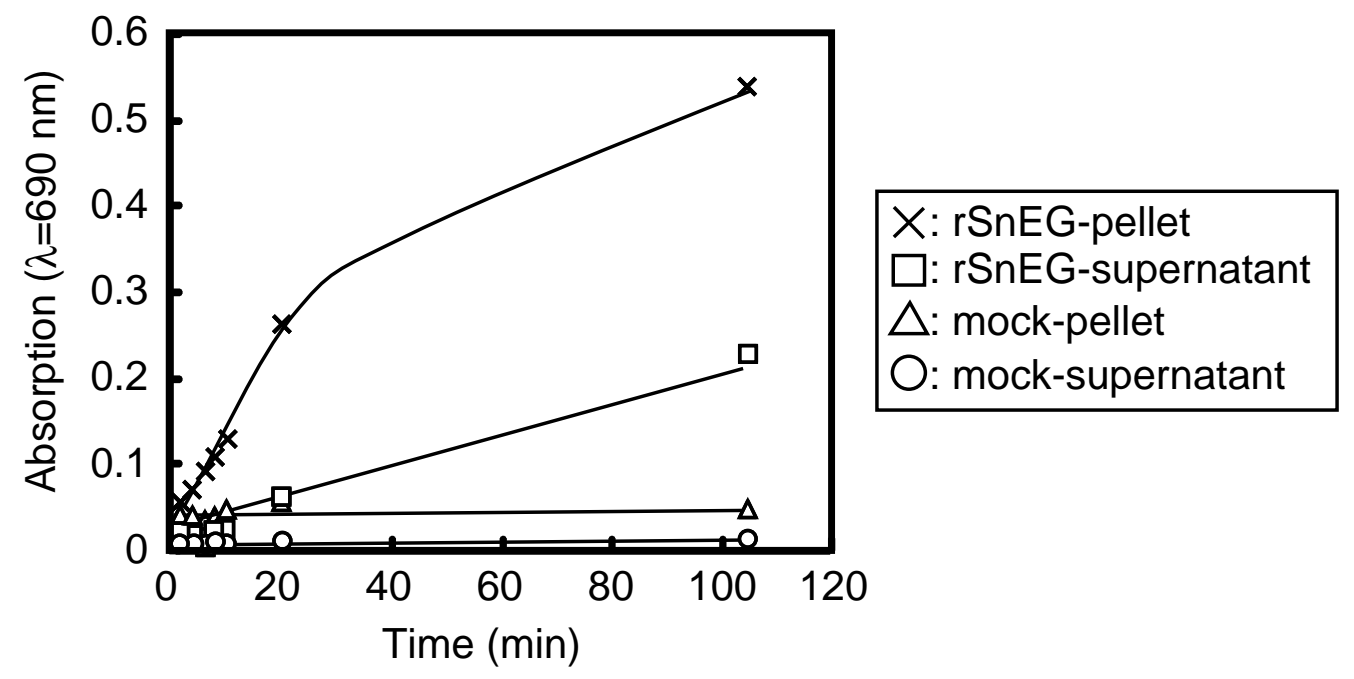

mock-supernatant: $0.00 \mathrm{U} / \mathrm{ml}$ mock-pellet: $0.00 \mathrm{U} / \mathrm{ml}$ rSnEG-supernatant: $0.037 \mathrm{U} / \mathrm{ml}$ rSnEG-pellet: $0.20 \mathrm{U} / \mathrm{ml}$

Fig. 2 


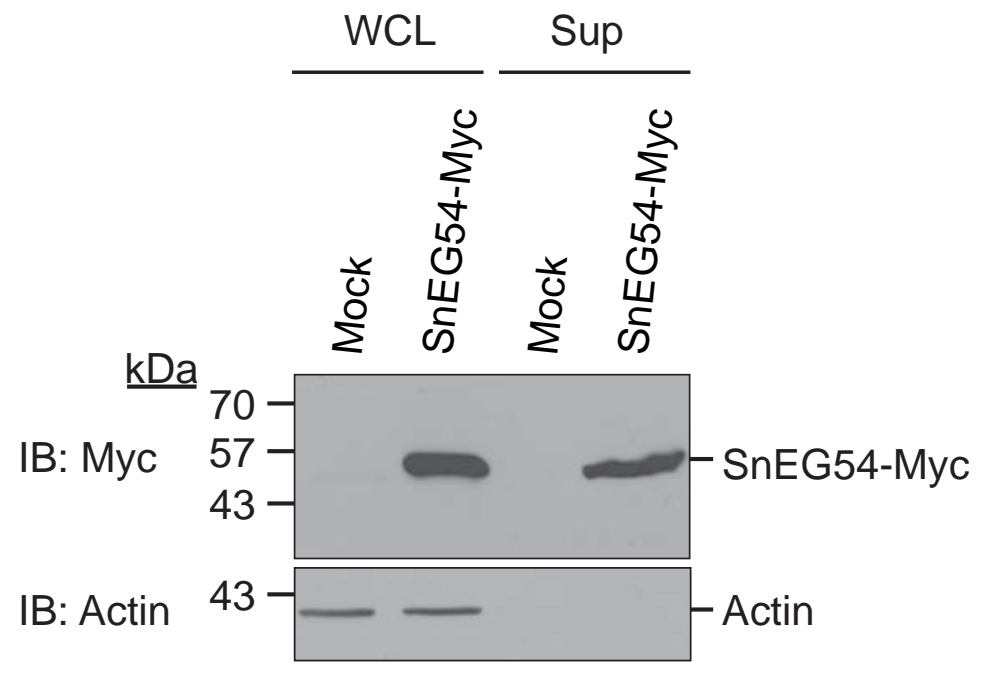

Fig. 3 


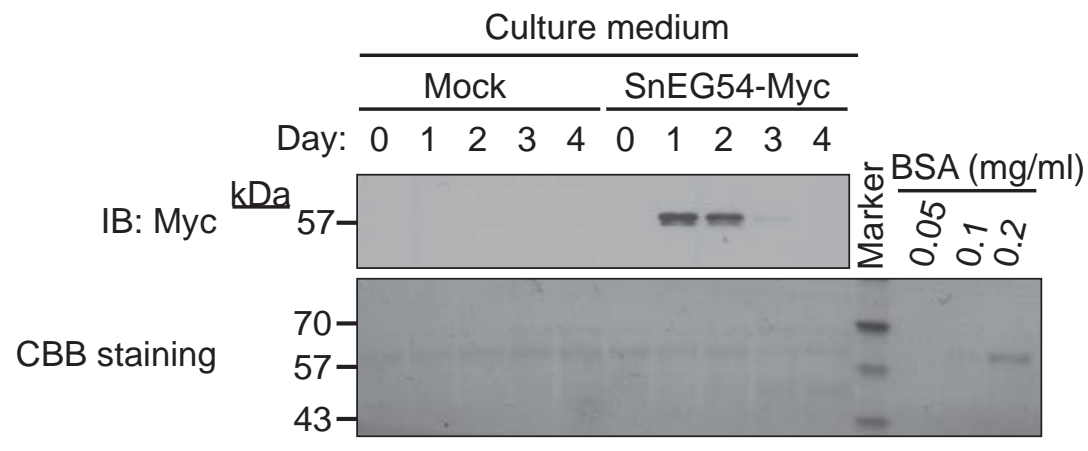

Fig. 4 